\title{
Methods to evaluate gut evacuation rates and predation using acoustic telemetry in the Tracy Fish Collection Facility primary channel
}

\author{
Andrew A Schultz ${ }^{1,2}$, Kevin K Kumagai ${ }^{3^{*}}$ and Brent B Bridges ${ }^{1}$
}

\begin{abstract}
Background: In the Sacramento-San Joaquin Delta, several salmonid species are listed as threatened or endangered. One potential cause of lower juvenile salmonid survival may be predation by striped bass (Morone saxatilis) and other piscivores. Acoustic telemetry is routinely used to estimate salmonid behavior and survival by releasing and detecting tagged juvenile salmonids with the assumption acoustic-tagged salmon are not consumed by predators. If this assumption is violated, behavior and survival estimates may be misinterpreted. A key consideration is the time taken by an acoustic tag to pass through the digestive tract of a predatory fish.

Results: All tagged dead juvenile Chinook salmon (Oncorhynchus tshawytscha) placed into the Tracy Fish Collection Facility (TFCF) primary channel were verified as being consumed by a predator and the tags evacuated from the predator's gut, via evaluation of two-dimensional (2D) tracks and detection signal patterns from single and multiple hydrophones. Tracks and signal patterns simultaneously showed after time of consumption. Salmon were traveling around the primary channel, moving both with and against flow in both a linear and non-linear manner indicative of a free-swimming fish. Given salmon were dead prior to consumption, we feel confident they were inside a predatory fish. Further support for this was provided by two previously tagged striped bass with active tags that consumed tagged dead salmon from our study and an unknown predator that consumed two tagged dead salmon from our study at points about 30 min apart. Mean tag evacuation time was 1.8 days, ranging from 1.2 to 2.7 days $(N=14, S D=0.49)$. Although not significant, we found a suggestive linear relationship $\left(r^{2}=0.23 ; d f=12 ; P<0.08\right)$ between mean water temperature during tag retention and tag evacuation time.

Conclusions: We have strong evidence in the ability to confirm predation and measure the rate at which free-swimming predatory fishes digestively pass acoustic tags that were implanted in Chinook salmon within the TFCF primary channel. Our results have possible application to other areas/systems depending on the physical characteristics of the site, design of the hydrophone array, and methods used.
\end{abstract}

Keywords: Acoustic tag, Predation, Evacuation, Telemetry, Striped bass, Salmon, Delta

\section{Background}

In the Sacramento-San Joaquin Delta (Delta), several salmonid species are listed as threatened or endangered [1-3]. Acoustic telemetry technology is a widespread and proven tool to study salmonid behavior and survival [4-6]. Use of acoustic telemetry technology in the Delta is ongoing; however, the full power of this analytical tool is only realized if it is appropriately implemented and

\footnotetext{
* Correspondence: kkumagai@htisonar.com

${ }^{3}$ Hydroacoustic Technology, Incorporated, 715 NE Northlake Way, Seattle, WA 98105, USA

Full list of author information is available at the end of the article
}

the results are properly analyzed and understood. It is widely recognized that non-native piscivores consume migrating salmonids throughout the Delta, with the striped bass (Morone saxatilis) of particular interest. There is evidence of predation on acoustic-tagged juvenile salmon which confounds analyses and interpretation of acoustic telemetry data [7,8]. Vogel's [8] conclusion from the author's evaluation of a large Delta-wide study exemplified the reason for concern, 'It appears we were frequently tracking dead salmon...inside predatory fish... 
making it very difficult to accurately estimate overall salmon survival, salmon survival by reach, and fish route selection....all of which were (and continue to be) key objectives'.

The Delta is the single largest source of California's water. Delta water is diverted and transported by two large pumping facilities: C.W. 'Bill' Jones Pumping Plant and Harvey O. Banks Pumping Plant. Both have fish salvage facilities upstream of the export flows to reduce the number of fishes entrained to the pumps and into the water deliveries. Both the federal Tracy Fish Collection Facility (TFCF) and the state Skinner Delta Fish Protective Facility use a behavioral-type louver bypass system to guide fishes out of the export canals and into collection tanks where the salvaged fishes are held and then transported and released back into the Delta. Inflow through the facilities attracts a variety of fishes, including threatened and endangered species, which in turn attracts predatory fishes such as the striped bass. Some study results have indicated high rates of predation upon acoustic-tagged salmonids at these salvage facilities $[8,9]$.

The time needed for an acoustic tag to pass through the digestive tract of most predatory fishes, hereafter referred to as evacuation rate, is largely unknown. Such information would assist in analyses of acoustic telemetry data. For example, salmonid survival estimates may use a variety of filters to differentiate salmonid and predator acoustic tag detections. Travel time is one such filter and in the Delta has ranged from 2.6 to 7.2 days for San Joaquin River to Chipps Island salmonid acoustic tag detections, depending on route [10]. As a result, time is an important variable in survival estimates. Determining evacuation rates of acoustic tags for free-swimming predatory fishes presents a difficult challenge in most field situations. The primary channel at TFCF provides an ideal location to study striped bass predation and evacuation rates as adult striped bass are thought to reside for moderate-long periods of time within the primary channel, and an acoustic hydrophone array, allowing collection of near-field two-dimensional (2D) data, is currently being maintained at this facility.

Our objective was to conduct a proof-of-concept experiment to determine if we could confirm predation of acoustic-tagged salmonids and measure time required for an acoustic tag to pass through the digestive tract of a free-swimming predatory fish using previously untested methods. Information gathered from this study will assist with the evaluation and interpretation of acoustic telemetry data on survival and movement of juvenile Chinook salmon (Oncorhynchus tshawytscha) and impact of predators such as the striped bass throughout the Central Valley of California, with possible application to other species and systems. Information gathered will prove valuable to TFCF-related studies employing acoustic tag technology, including evaluation of movement and predation of fishes within and near TFCF.

\section{Results}

All tagged dead juvenile Chinook salmon placed into the TFCF primary channel were verified as being consumed by a predator, and the tags were evacuated from the predator's gut via evaluation of $2 \mathrm{D}$ tracks and detection signal patterns from single and multiple hydrophones (Figures 1, 2, 3, 4, 5 and 6; see Additional file 1 for animation of Figures 1, 2, 3 and 4). Tracks and signal patterns simultaneously showed after time of consumption salmon were traveling around the primary channel, moving both with and against flow in both a linear and nonlinear manner indicative of a free-swimming fish. Given salmon were dead prior to consumption, we feel confident they were inside a predatory fish. Further support for this was provided by two previously tagged striped bass with active acoustic tags that consumed tagged dead salmon from our study and an unknown predator that consumed two tagged dead salmon at points about 30 min apart. One of the two previously tagged striped bass ate two tagged salmon at points over 4 days apart.

Mean tag evacuation time was 1.8 day, ranging from 1.2 to 2.7 days $(N=14, \mathrm{SD}=0.49)$ (Table 1$)$. Mean water temperature over the course of the study period was $23.3^{\circ} \mathrm{C}(N=466 ; \mathrm{SD}=1.5$; range $=21.4$ to 26.5$)$. Mean fork length (FL) of tagged salmon was $146.6 \mathrm{~mm}(N=$ 14 ; $\mathrm{SD}=7.6$; range $=131$ to 165 ). Although not significant, we found a suggestive linear relationship $\left(r^{2}=0.23\right.$; $d f=12 ; P<0.08)$ between mean water temperature during tag retention and tag evacuation time (Figure 7). The regression equation for this relationship was: days to tag evacuation time $=5.71-0.17$ * water temperature. Length of tagged salmon was not included in the regression analysis as no pattern or apparent relationship appeared to exist between this variable and tag evacuation time.

\section{Discussion and conclusions}

We have strong evidence in the ability to confirm certain predation events and measure the rate at which freeswimming predatory fishes digestively pass acoustic tags that were implanted in Chinook salmon within the TFCF primary channel. Our results have possible application to other areas/systems depending on the physical characteristics of the site, design of the hydrophone array, and methods used.

Due to the physical nature of the TFCF trash rack and primary louvers, cleaning of the primary louvers and prey fishes attracted by export flows, the TFCF primary channel often builds a significant number of striped bass both in front of and behind (inside the primary channel) the trash rack (TFCF unpublished data and personal observation). These predators undoubtedly impact TFCF's 


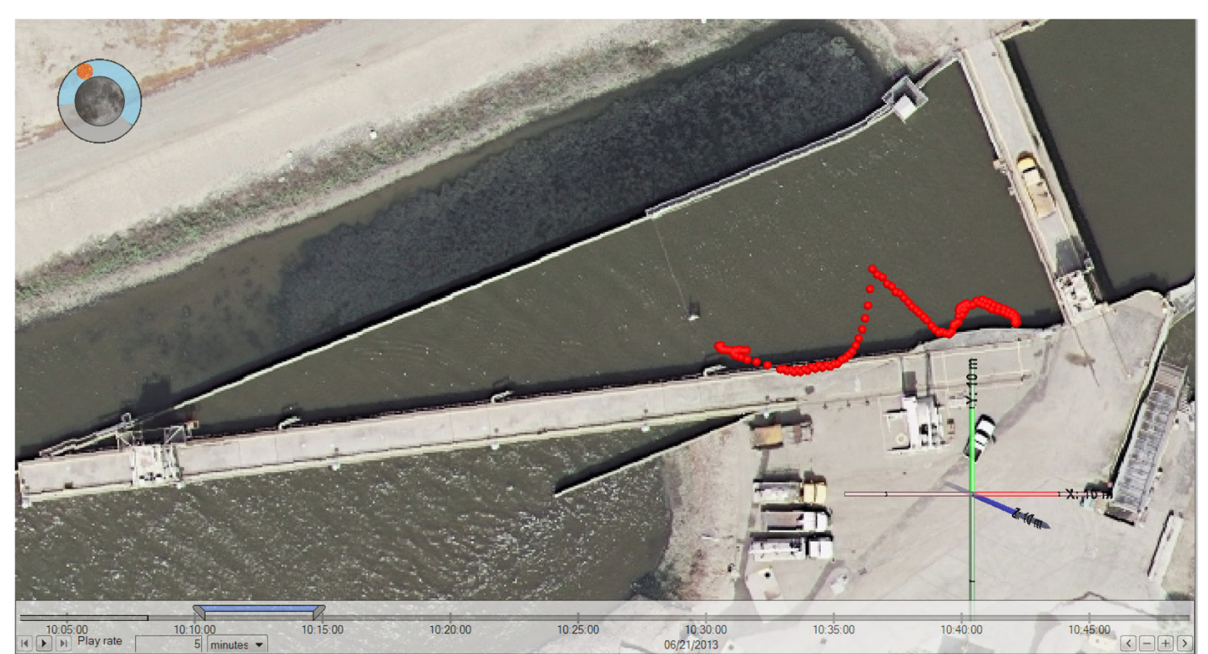

Figure 1 Acoustic signal track. Acoustic signal track (about 10:10 to 10:15 AM on 21 June 2013) showing presence and movement of a striped bass (red spheres) in the Tracy Fish Collection Facility primary channel.

salvage rates and have the potential to impact results of experiments conducted at the facility and/or Delta-wide experiments involving the facility. Methodologies tested in this study can assist in estimating and evaluating such predatory impacts. Bridges et al. (unpublished data) are currently evaluating use of methods used in this study to estimate predator density in the TFCF primary channel.

Hiding transmitters inside tethered bait for the purposes of voluntary intragastric tagging is known, especially in marine environments/species [11-14]. Such techniques eliminate the stress (for example, capture, handling, surgical) associated with most common tagging procedures. This in turn increases the likelihood tagged fishes will exhibit more natural behaviors and physiological conditions.

Based on prior observations via gill-netting and angling (TFCF unpublished data), we assumed most, if not all, of the predators taking the tethered salmon were striped bass. Direct observations and acoustic telemetry data from studies following ours, but using similar methods, provide further evidence that predatory fishes in the TFCF primary channel, taking prey fish used per methods outlined in our paper, are most likely striped bass (Schultz et al. unpublished data). Regardless, caution is likely warranted in use of the results due to potential inter-species differences.

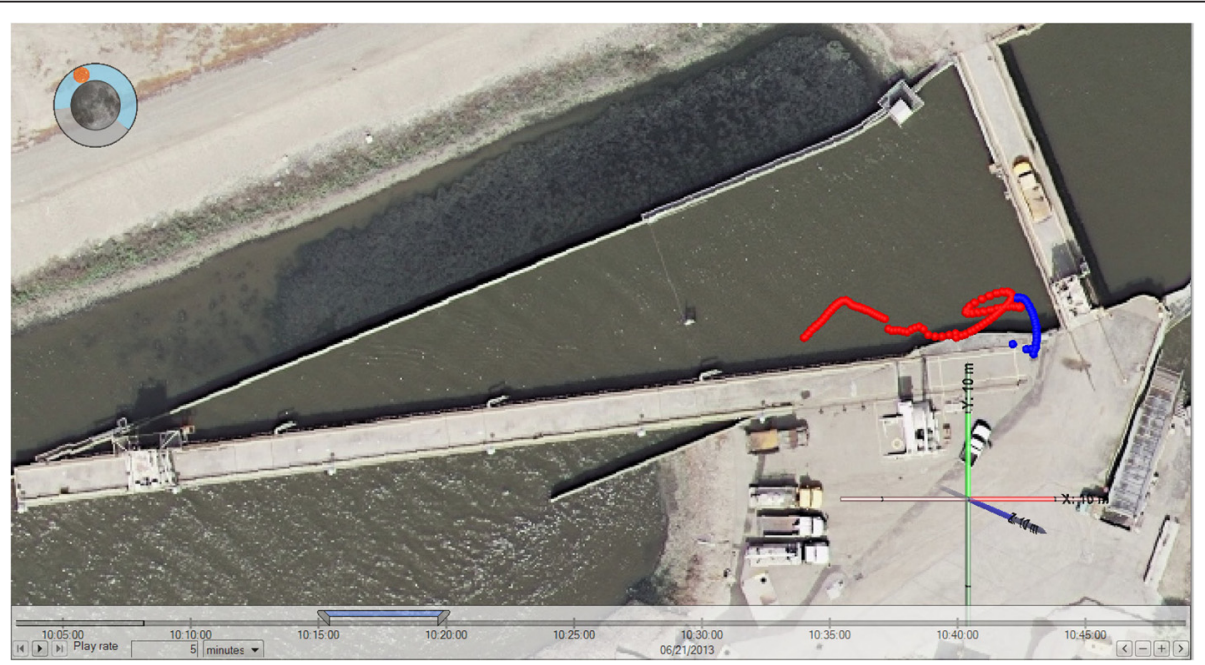

Figure 2 Acoustic signal tracks. Continuation of the acoustic signal tracks (about 10:15 to 10:20 AM on 21 June 2013) from Figure 1 showing presence and movement of the striped bass (red spheres) with apparent consumption of a tagged euthanized Chinook salmon (blue spheres) in the Tracy Fish Collection Facility primary channel at about 10:20 AM. 


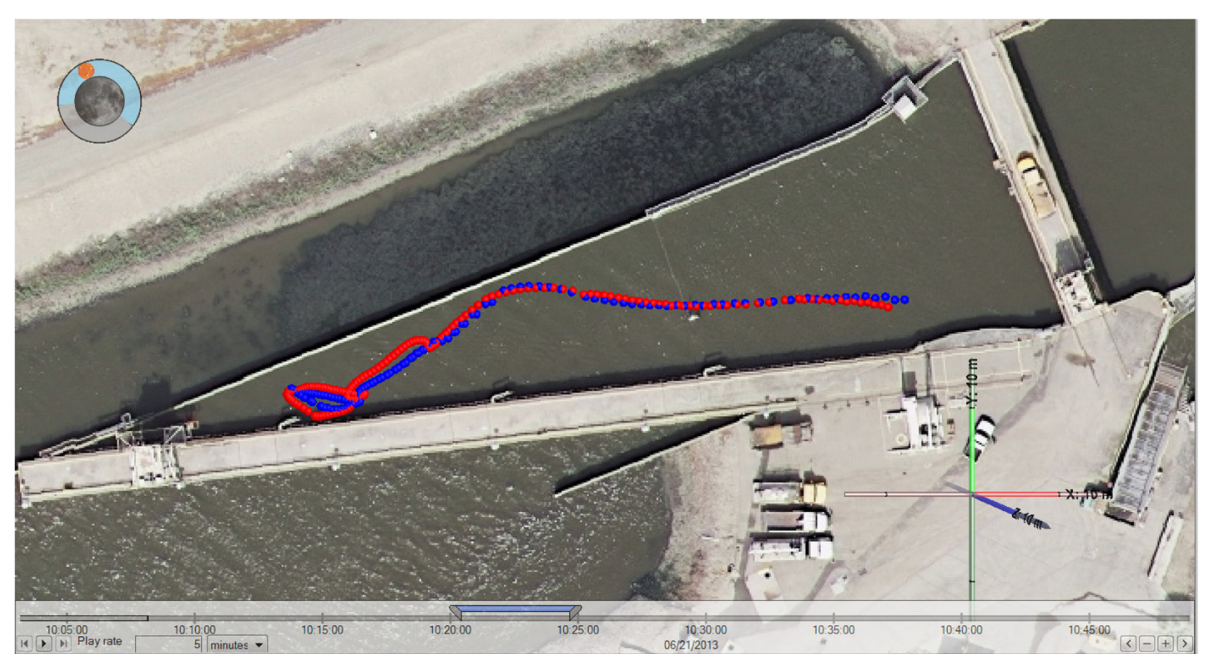

Figure 3 Acoustic signal tracks. Continuation of the acoustic signal tracks (about 10:20 to 10:25 AM on 21 June 2013) from Figure 2 showing matching movements of the striped bass (red spheres) and tagged euthanized Chinook salmon (blue spheres). Matching movements remained for almost two days in the Tracy Fish Collection Facility primary channel.

Evacuation times for this study were shorter than evacuation times for prototype predation acoustic tags $(1.1 \mathrm{~g})$ tested in relatively sedentary striped bass held in the laboratory at about $16^{\circ} \mathrm{C}$ (Schultz et al. unpublished data). This is perhaps not unexpected as temperatures in our experiment were noticeably higher and the tags smaller and lighter. The relationship between water temperature and metabolic rate is well known for fishes including the striped bass [15], and increasing water temperatures are known to increase gastric evacuation in fishes up to a certain threshold temperature [16,17]. It is assumed the metabolic rate and corresponding gastric evacuation rate of striped bass in the TFCF primary channel is related to water temperature in a similar fashion. It is currently unknown how this relationship may affect the evacuation of acoustic tags. Petersen and Barfoot [18] suggested the process for passive integrated transponder tag evacuation could be largely explained by temperature alone. The calendar dates and water temperatures during our study period are largely outside of that observed when salmonids are typically migrating through TFCF, and thus, results should be taken as intended, for purposes of evaluating the methodologies used. Size, gut fullness, and frequency of feeding of the

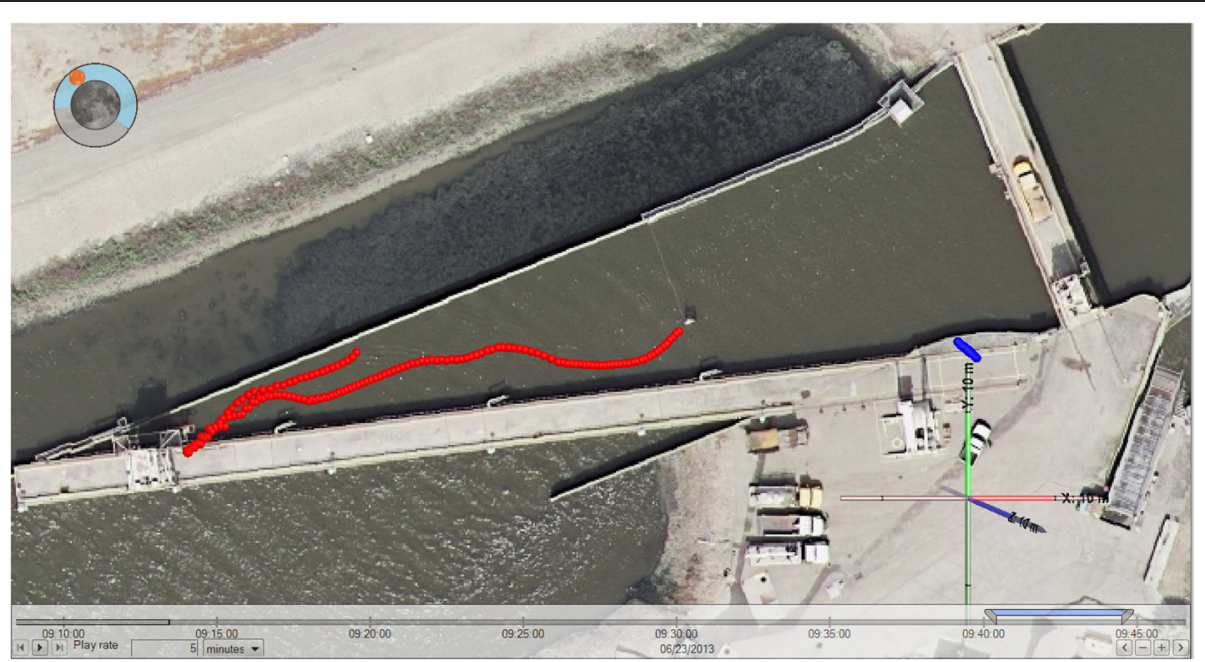

Figure 4 Acoustic signal tracks. Continuation of the acoustic signal tracks (about 9:40 to 9:45 AM on 23 June 2013) from Figure 3 showing movement of the striped bass (red spheres) and no movement of the acoustic tag (blue spheres) thought to be evacuated from the gut of the same striped bass at about 9:15 AM on 23 June 2013 in the Tracy Fish Collection Facility primary channel. 


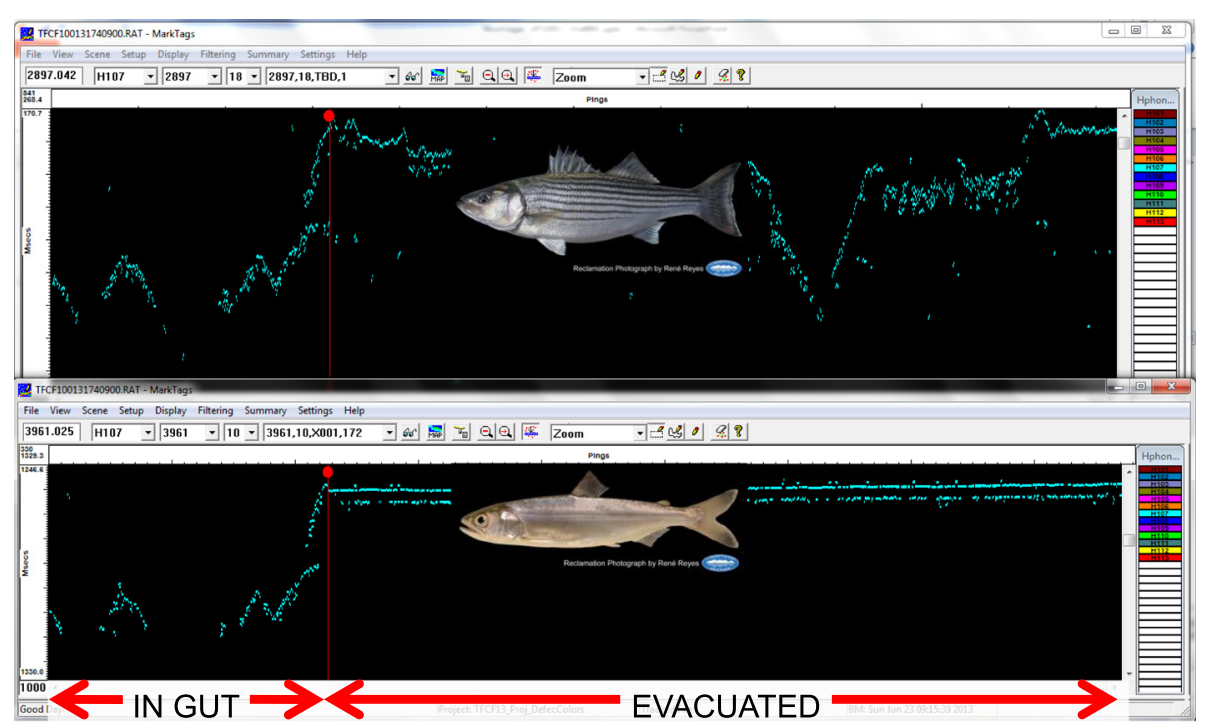

Figure 5 Matching acoustic signals - single hydrophone. Shown are matching acoustic signals from a striped bass (top) and a tagged euthanized Chinook salmon (bottom) thought to be consumed by the same striped bass, with subsequent gut evacuation of the latter from a single hydrophone in the Tracy Fish Collection Facility primary channel.

predators consuming our study salmon were largely unknown, but such variables and others are known to affect gastric evacuation experiments [19].

Further research into gut evacuation rates of predators consuming acoustic-tagged fishes will assist in analyses of acoustic telemetry data. Studies should focus on how factors such as water temperature, feeding frequency, stomach fullness, tag size, and predator size and species impact results. The U.S. Bureau of Reclamation is currently collecting similar data in the TFCF primary channel across varying water temperature conditions.

\section{Methods}

\section{Location}

The study occurred at TFCF's Tracy Aquaculture Facility and primary channel (Byron, CA; Figure 8) from 21 June

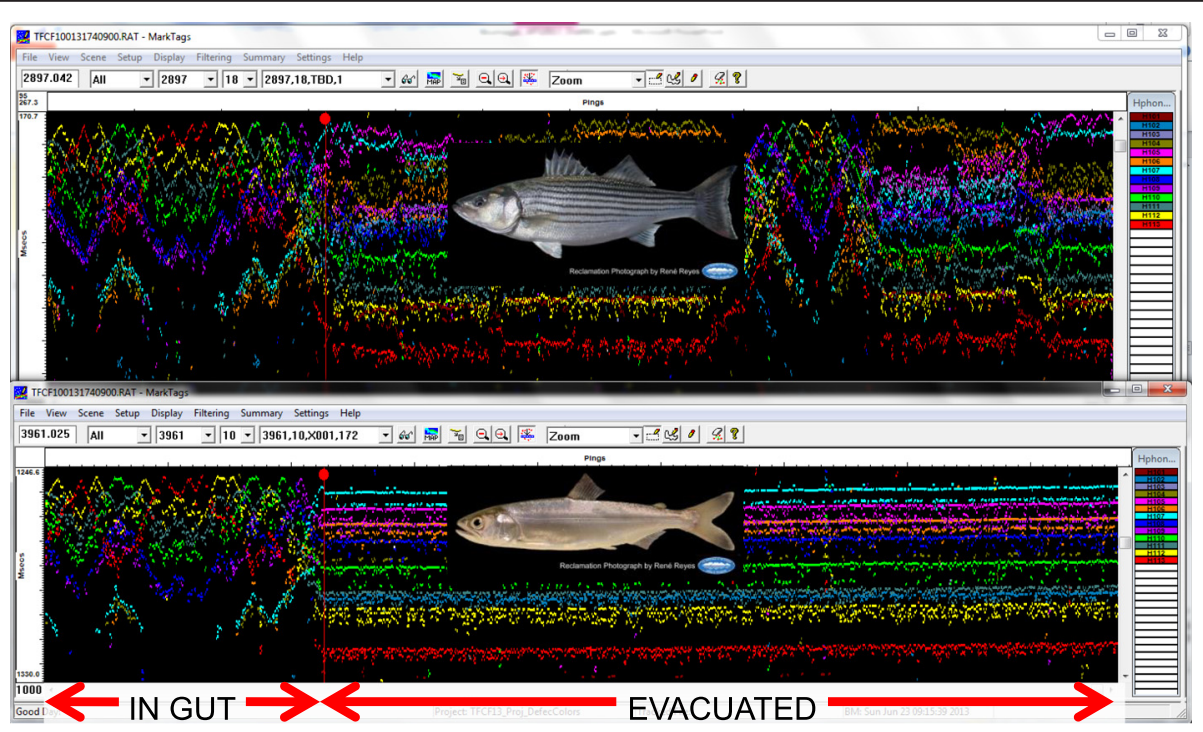

Figure 6 Matching acoustic signals - multiple hydrophones. Shown are matching acoustic signals from a striped bass (top) and a tagged euthanized Chinook salmon (bottom) thought to be consumed by the same striped bass, with subsequent gut evacuation of the latter from multiple hydrophones in the Tracy Fish Collection Facility primary channel. 
Table 1 Summary of acoustic tag data with date/time consumed and evacuated versus water temperature

\begin{tabular}{|c|c|c|c|c|c|}
\hline Salmon tag code & $\begin{array}{l}\text { Salmon length } \\
(\mathrm{mm} \mathrm{FL})\end{array}$ & $\begin{array}{l}\text { Date/time tag } \\
\text { consumed }\end{array}$ & $\begin{array}{l}\text { Date/time tag } \\
\text { evacuated }\end{array}$ & $\begin{array}{l}\text { Elapsed time of } \\
\text { tag evacuation (days) }\end{array}$ & $\begin{array}{l}\text { Water temperature } \\
\text { during tag retention }\left({ }^{\circ} \mathrm{C}\right)\end{array}$ \\
\hline $3961.10^{\mathrm{a}}$ & 165 & 21 June 2013 10:20 & 23 June 2013 9:15 & 1.96 & 22.22 \\
\hline $6803.10^{\mathrm{b}}$ & 143 & 25 June 2013 15:28 & 28 June 2013 8:36 & 2.71 & 23.08 \\
\hline 5333.10 & 145 & 25 June 2013 15:29 & 27 June 2013 12:41 & 1.88 & 22.66 \\
\hline $6215.10^{a}$ & 149 & 25 June 2013 15:35 & 27 June 2013 16:01 & 2.02 & 22.73 \\
\hline 3667.10 & 142 & 25 June 2013 15:37 & 27 June 2013 0:09 & 1.36 & 22.50 \\
\hline 3275.10 & 152 & 25 June 2013 15:39 & 27 June 2013 13:31 & 1.91 & 22.68 \\
\hline 6509.10 & 145 & 25 June 2013 15:56 & 27 June 2013 15:28 & 1.98 & 22.71 \\
\hline $4647.10^{b}$ & 140 & 25 June 2013 16:00 & 28 June 2013 8:36 & 2.69 & 23.09 \\
\hline 4059.10 & 148 & 25 June 2013 16:01 & 27 June 2013 5:54 & 1.58 & 22.58 \\
\hline 5725.10 & 151 & 25 June 2013 16:10 & 27 June 2013 1:02 & 1.37 & 22.52 \\
\hline 4843.10 & 131 & 29 June 2013 12:05 & 30 June 2013 17:08 & 1.21 & 25.61 \\
\hline $3471.10^{c}$ & 145 & 29 June 2013 12:14 & 30 June 2013 21:08 & 1.37 & 25.67 \\
\hline 6705.10 & 151 & 29 June 2013 12:40 & 30 June 2013 17:06 & 1.18 & 25.62 \\
\hline 5921.10 & 145 & 29 June 2013 12:46 & 1 July 2013 2:06 & 1.56 & 25.75 \\
\hline
\end{tabular}

${ }^{a}$ Consumed by striped bass (2897.18) of known length ( $588 \mathrm{~mm} \mathrm{FL);}{ }^{\mathrm{b}}$ consumed by same predator of unknown length; ${ }^{\mathrm{C}}$ consumed by striped bass ( 2729.18$)$ of known length ( $505 \mathrm{~mm} \mathrm{FL).} \mathrm{Elapsed} \mathrm{times} \mathrm{for} \mathrm{acoustic} \mathrm{tags} \mathrm{to} \mathrm{pass} \mathrm{through} \mathrm{the} \mathrm{guts} \mathrm{of} \mathrm{predatory} \mathrm{fishes} \mathrm{are} \mathrm{listed} \mathrm{for} \mathrm{each} \mathrm{unique} \mathrm{tag} \mathrm{code/Chinook} \mathrm{salmon}$ pairing released in the Tracy Fish Collection Facility (Byron, CA) primary channel. Mean water temperatures during retention of tags in predators are provided, as are information on predators when known. FL, fork length.

2013 to 1 July 2013. The TFCF primary channel is at the mouth of the Delta Mendota Intake Canal (DMIC) and varies in depth from about 4.6 to $5.1 \mathrm{~m}$ depending on tidal influences and pumping. Overall flow in the primary channel varies from negative, during no pumping and tidal action, up to about $142 \mathrm{~m}^{3} / \mathrm{s}$ when pumping is at maximum. Water velocities within the primary channel vary throughout due to channel characteristics and changes in pumping/flow (TFCF unpublished data). Entrained fishes are either diverted toward bypasses to

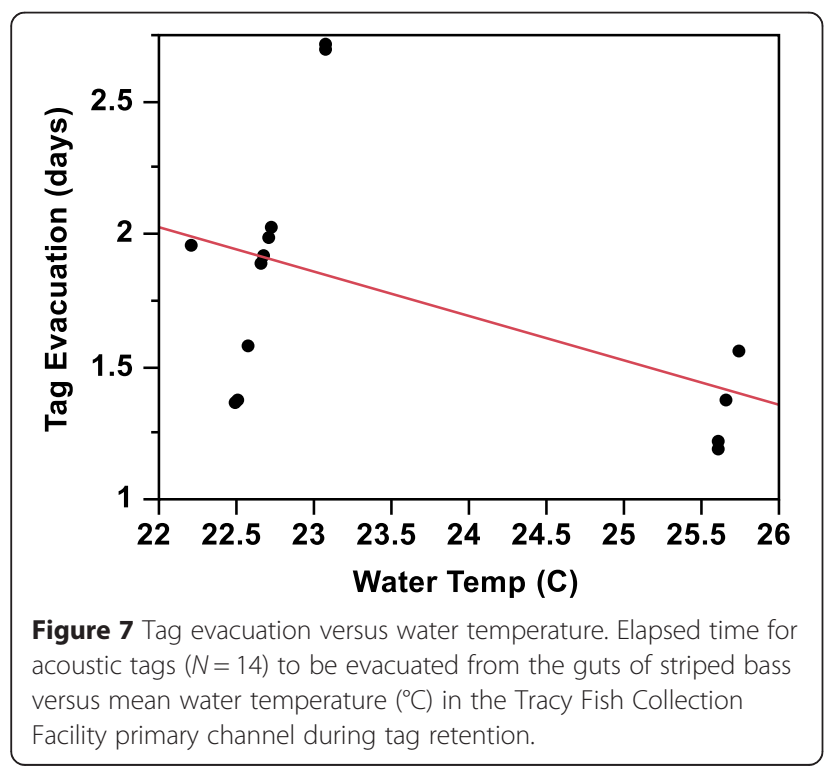

holding tanks to be salvaged or lost to exports downstream. At the head of the TFCF primary channel, a trash rack comprised of vertical metal bars (slot width about $57 \mathrm{~mm}$ ) prevents large debris from entering the facility and is also thought to serve as a barrier to larger fishes (about $500 \mathrm{~mm}$ FL or more). At the downstream end of the primary channel, primary louver panels (about $2.5 \mathrm{~m}$ wide) are angled ( $15^{\circ}$ to flow) to divert fishes to one side. Each panel is comprised of vertical metal bars (slot width about $23 \mathrm{~mm}$ ) located at an angle to the inflow and serve to guide fishes into one of four adjacent bypasses. Each panel is regularly lifted for cleaning, allowing larger fishes an opportunity to move into the primary channel from the DMIC or vice versa.

\section{Acoustic tags and detection system}

Acoustic tags (Hydroacoustic Technology, Inc., Seattle, WA, USA (HTI), Model 800; $0.5 \mathrm{~g} ; 13.5 \mathrm{~mm}$ length and $6.1 \mathrm{~mm}$ width; $307 \mathrm{kHz}$ frequency) were removed from recaptured Chinook salmon used for an unrelated facility efficiency study (Karp et al. unpublished data) and reprogrammed using pulse-rate encoding for use in this experiment. Such encoding provides increased detection range, improves the signal-to-noise ratio and pulsearrival resolution, and decreases position variability when compared to other types of acoustic tags [20]. The Model 800 HTI Acoustic Tags were encapsulated with an inert, low toxicity resin compound.

Acoustic hydrophones were optimally positioned in the TFCF primary channel to allow for distinguishing 


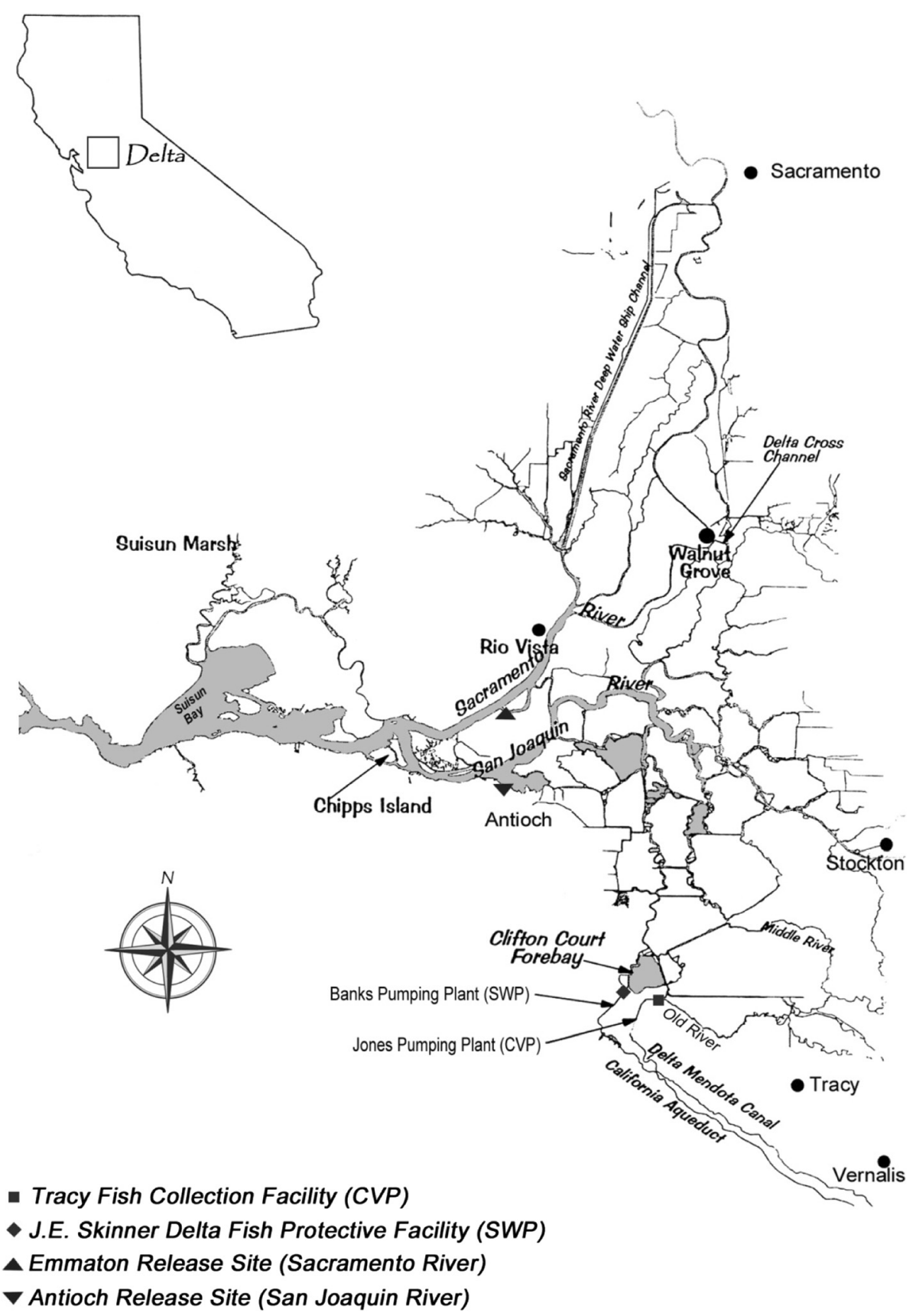

Figure 8 Map of the Sacramento-San Joaquin Delta showing location of the Tracy Fish Collection Facility.

fine-scale 2D movement (Figure 9; Karp et al. unpublished data). The acoustic array within the primary channel consisted of eight hydrophones (HTI, Model 590 Hydrophone $(N=7)$ and Model 594 Low-Profile Hydrophone $(N=1)$ ). Hydrophones were connected via cables (HTI, Model 690 Hydrophone Cables) to a receiver (HTI, Model 290 Acoustic Tag Receiver). Hydrophones were installed approximately in the same plane to minimize the $2 \mathrm{D}$ positioning variability of the acoustic tags. Hydrophones were deployed in an attempt to include each hydrophone as a member of at least one combination of three hydrophones that formed a nearly equilateral triangle. However, the primary channel's irregular shape caused some combinations to deviate from the ideal equilateral triangle shape. The $2 \mathrm{D}$ tag positions were calculated using the 


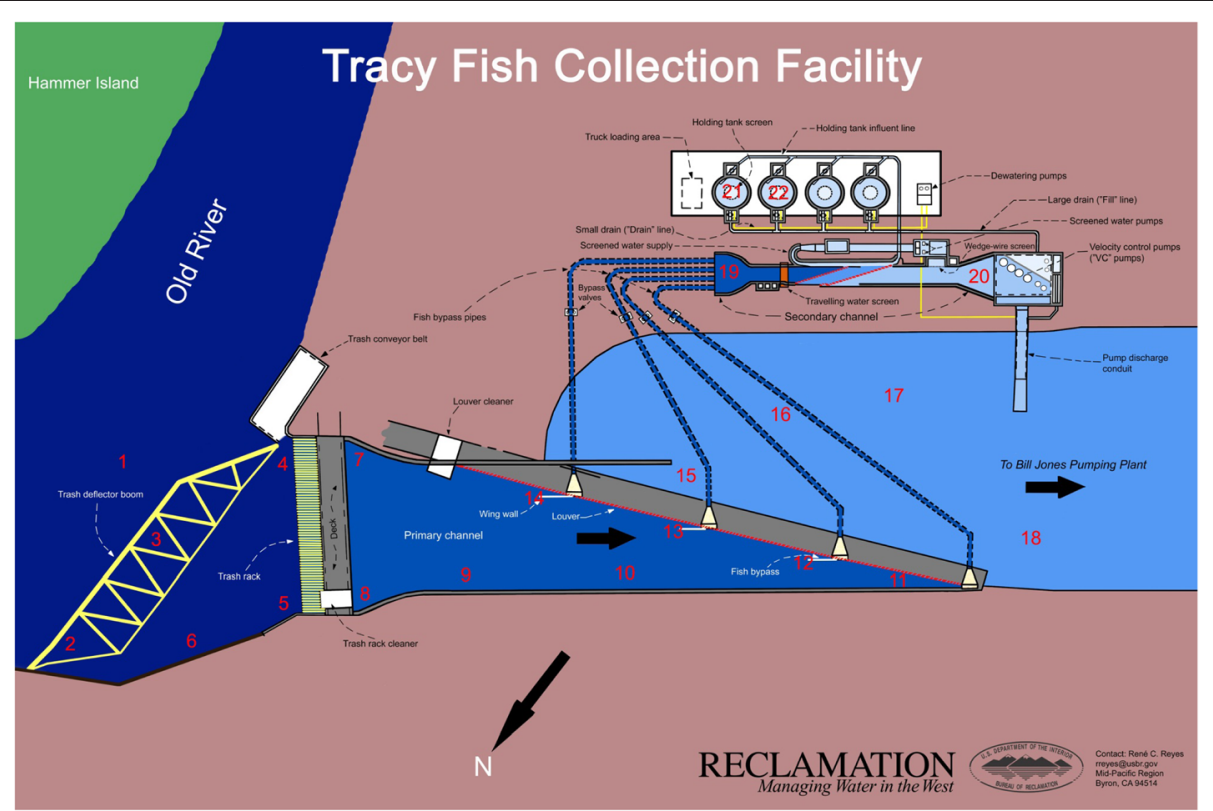

Figure 9 Schematic of the Tracy Fish Collection Facility with numbered hydrophone placements (hydrophone placements from Karp et al. unpublished data).

arrival time differences of tag signals at each hydrophone (HTI, AcousticTag Program). The 2D positioning required detection of tag signals by a minimum of three hydrophones.

\section{Field component and procedure}

Acoustic tags were inserted through the mouth into the gastric area of recently euthanized (using sharp blows to the head) juvenile Chinook salmon $(N=14)$. Salmon were then immediately tethered to a monofilament fishing line by a small metal clip on the tip of the lower jaw and lowered via a fishing pole into the TFCF primary channel. Time of consumption occurred when the tethered salmon was felt to be pulled off the clip by a predatory fish in the primary channel and was not attached to the clip after being reeled up for immediate inspection. Time at consumption and evacuation were verified via evaluation of 2D tracks and detection signal patterns from single and multiple hydrophones using HTI's Acoustic Tag Software Suite and Eonfusion (Hobart, Tasmania, Australia).

Size and weight of predators residing within the primary channel were largely unknown outside of seven acoustic-tagged striped bass, confirmed using methods just described, as remaining in the primary channel from prior facility efficiency trials (Karp et al. unpublished data). Water temperature data were recorded using multi-parameter sondes located just upstream of the TFCF primary channel (TFCF unpublished data).

\section{Additional file}

Additional file 1: Animation of Figures 1, 2, 3 and 4. Animation

displays time at consumption and evacuation developed with Eonfusion.

\section{Abbreviations}

2D: two-dimensional; Delta: Sacramento-San Joaquin Delta; DMIC: Delta Mendota Intake Canal; FL: fork length; HTI: Hydroacoustic Technology, Incorporated; TFCF: Tracy Fish Collection Facility.

\section{Competing interests}

The study occurred within the property boundary of AS and BB's employer. Equipment, software and tags used were purchased from KK's employer.

\section{Authors' contributions}

AS and KK contributed to the design, conduct, analysis, interpretation, and written account of this study. BB contributed to the design and provided consultation on methods and interpretation. All authors read and approved drafts and the final manuscript.

\section{Acknowledgements}

This study would not have been possible without the resources and staff assistance provided by the Bureau of Reclamation's Tracy Fish Collection Facility, Tracy Aquaculture Facility, and Tracy Fish Facility Improvement Program. Special thanks to the Bureau of Reclamation's Technical Service Center for providing tags and equipment and the California Department of Water Resources for providing equipment. We thank the editors and two anonymous referees for comments that improved the manuscript. Final thanks to Hydroacoustic Technology, Incorporated for providing equipment and software support.

\section{Author details}

${ }^{1}$ Bureau of Reclamation, Tracy Fish Collection Facility, Tracy Field Office, 16650 Kelso Rd, Byron, CA 94514, USA. ${ }^{2}$ Current Address: Bureau of Reclamation, Bay-Delta Office, 801 I Street, Suite 140, Sacramento, CA 95814, USA. ${ }^{3}$ Hydroacoustic Technology, Incorporated, 715 NE Northlake Way, Seattle, WA 98105, USA. 
Received: 8 January 2015 Accepted: 8 April 2015

Published online: 09 May 2015

\section{References}

1. National Marine Fisheries Service. Endangered and threatened species: threatened status for two ESUs of steelhead in Washington, Oregon, and California. Fed Regist. 1998;63(53):13347-71.

2. National Marine Fisheries Service. Endangered and threatened species: final listing determinations for 16 ESUs of west coast salmon, and final 4(d) protective regulations for threatened salmonid ESUs. Fed Regist. 2005;70(123):37160-204.

3. National Marine Fisheries Service. Endangered and threatened species: final listing determinations for 10 distinct population segments of west coast steelhead. Fed Regist. 2006;71(3):834-62.

4. Heupel MR, Webber DM. Trends in acoustic tracking: where are the fish going and how will we follow them. Am Fish Soc Symp. 2011;76

5. McMichael GA, Eppard MG, Carlson TJ, Carter JA, Ebberts BD, Brown RS, et al. The juvenile salmon acoustic telemetry system: a new tool. Fisheries. 2010;35(1):9-22.

6. Romine JG, Perry RW, Johnston SV, Fitzer CW, Pagliughi SW, Blake AR. Identifying when tagged fishes have been consumed by piscivorous predators: application of multivariate mixture models to movement parameters of telemetered fishes. Animal Biotelemetry. 2014;2:3.

7. Delta Science Program Review Panel. The Vernalis Adaptive Management Program (VAMP): report of the 2010 review panel, Prepared for the Delta Science Program. 2010. p. 45.

8. Vogel DA. Evaluation of acoustic-tagged juvenile Chinook salmon movements in the Sacramento-San Joaquin Delta during the 2009 Vernalis Adaptive Management Program, Prepared for the Vernalis Adaptive Management Program. Natural Resource Scientists, Inc: Red Bluff, CA; 2010.

9. Clark KW, Bowen MD, Mayfield RB, Zehfuss KP, Taplin JD, Hanson CH. Quantification of pre-screen losses of juvenile steelhead within Clifton Court Forebay, Technical report, California Department of Water Resources, Sacramento. 2009.

10. Buchanan RA, Skalski JR, Brandes PL, Fuller A. Route use and survival of juvenile Chinook salmon through the San Joaquin River Delta. N Am J Fish Manag. 2013;33:216-29.

11. Armstrong JD, Johnstone ADF, Lucas MC. Retention of intragastric transmitters after voluntary ingestion by captive cod, Gadus morhua L. J Fish Biol. 1992;40(1):135-7.

12. Bellquist $L F$, Lowe $C G$, Caselle JE. Fine-scale movement patterns, site fidelity, and habitat selection of ocean whitefish (Caulolatilus princeps). Fish Res. 2008;91(2):325-35.

13. Winger PD, Walsh SJ. Tagging of Atlantic cod (Gadus morhua) with intragastric transmitters: effects of forced insertion and voluntary ingestion on retention, food consumption and survival. J Appl Ichthyol. 2001;17(5):234-9.

14. Winger PD, McCallum BR, Walsh SJ, Brown JA. Taking the bait: in situ voluntary ingestion of acoustic transmitters by Atlantic cod (Gadus morhua). Hydrobiologia. 2002;483:287-92.

15. Kruger RL, Brocksen RW. Respiratory metabolism of striped bass, Morone saxatilis (Walbaum), in relation to temperature. J Exp Mar Biol Ecol. 1978;31(1):55-66.

16. Bernreuther M, Temming A, Herrmann JP. Effect of temperature on the gastric evacuation in sprat Sprattus sprattus. J Fish Biol. 2009;75(7):1525-41.

17. Specziár A. In situ estimates of gut evacuation and its dependence on temperature in five cyprinids. J Fish Biol. 2002;60(5):1222-36.

18. Petersen JH, Barfoot CA. Evacuation of passive integrated transponder (PIT) tags from northern pikeminnow consuming tagged juvenile Chinook salmon. N Am J Fish Manag. 2003;23:1265-70.

19. Bromley PJ. The role of gastric evacuation experiments in quantifying the feeding rates of predatory fish. Rev Fish Biol Fish. 1994;4(1):36-66.

20. Ehrenberg JE, Steig TW. A study of the relationship between tag-signal characteristics and achievable performances in acoustic fish-tag studies. ICES J Mar Sci. 2009;66:1278-83.

\section{Submit your next manuscript to BioMed Central and take full advantage of:}

- Convenient online submission

- Thorough peer review

- No space constraints or color figure charges

- Immediate publication on acceptance

- Inclusion in PubMed, CAS, Scopus and Google Scholar

- Research which is freely available for redistribution

Submit your manuscript at www.biomedcentral.com/submit 